\title{
Research on the Trend of Yen Exchange Rate and International Crude oil Price Fluctuation Affected by Japan's Earthquake
}

\author{
Li Xiaoguang $^{1}$, Li Menggang ${ }^{2}$ \\ ${ }^{1}$ School of Economics and Management, Beijing Jiaotong University (China) \\ ${ }^{2}$ China Center for Industrial Security Research, Beijing Jiaotong University (Cbina) \\ xiaoguangli@foxmail.com, morganli@,vip.sina.com
}

\section{Abstract:}

Purpose: Whether this earthquake would become a turning point of the high oil price and whether it would have big impact on yen exchange rate are two issues to be discussed in this paper..

Design/methodology7approach: To analyze deeply the internal relations between changes in yen exchange rate caused by Japan's earthquake and price fluctuation of international crude oil, this research chooses middle rate of yen exchange rate during the 45 days around Japan's earthquake and price data of international crude oil to do an empirical study, uses VAR model and HP trend decomposition to estimate the mutual effect of yen exchange rate change and price fluctuation of international crude oil in this period.

Findings: It has been found in the empirical study with VAR model and HP filter decomposition model on the yen exchange rate and the international crude oil price fluctuation during 45 days around Japan's earthquake that: the fluctuation of yen exchange rate around the earthquake is one of the main reasons for the drastic fluctuation of international crude oil price in that period. The fluctuation of international crude oil price directly triggered by yen exchange rate occupies $13.54 \%$ of its total variance. There is a long-term interactive relationship between yen exchange rate and international crude oil price. The upward trend of 
international crude oil price after the earthquake was obvious, while yen exchange rate remained relatively stable after the earthquake.

Originality/value: As economic globalization goes deeper, the influence of natural disasters on international financial market and world economy will become more and more obvious. It has a great revelatory meaning to studying further each kind of natural disaster's impacts on international financial market and world economics.

Keywords: yen exchange rate, international crude oil price, Japan's earthquake

\section{Introduction}

Since the establishment of Jamaica System, major capitalist countries in the world generally have built the floating exchange rate system. Though U.S. dollar is not the single anchor currency of domestic currency changes of countries in the world since the Bretton Woods System collapsed, it still maintains the function of world currency and up to now still takes the function of major international reserve and international settlement as one of the few hard currencies in the world. Since economies of most countries were in decline with the outbreak of 2007 world financial crisis. Countries took low interest rate or large-scale fiscal stimulus plan one after another. Fed chairman Ben Bernanke et al. continued easy-money policy of Alan Greenspan's period and it led to global flood of liquidity. Prices of international energy and staple commodities climbed and the world economy fell into inflation generally. Low economic growth, high inflation rate and high unemployment rate were the features of macro-economy of most countries in this period. American continuous fiscal stimulus plans made the fiscal deficit of the U.S. federal government increase sharply. The devaluation expectation of dollar emerged and international investors began to look for alternative solutions. Yen and Euro have become the best safe-haven currencies instead of U.S. dollar since the financial crisis. As the financial hegemony of dollar was queried, countries required to reform existing international financial system, substitute the single dollar regime with a basket of currencies to avoid capital loss produced by devaluation of dollar. The prices of international staple commodities and energy began to be pegged to other currencies.

Today economic globalization is accelerated and global collocation of capital and currency has become a trend. With the world financial markets becoming increasingly interdependent, the micro-economic operational status and stability of any country is an essential condition for the stability of global financial market. Japan's earthquake damaged its entity economy seriously and lessened the possibility that Japan's economy accelerated its recovery since the 2007 financial crisis. At the same time the quick backflow of global yen by the influence of Japan's 
earthquake intensified the fluctuation of foreign exchange market. Yen appreciated quickly and international crude oil price was pushed up, which led to the crash of global stock market. To suppress the fluctuation of financial market brought by further quick appreciation of yen, the Group of Seven (G7) announced on March 18 to intervene foreign exchange market jointly. Bank of Japan also carried out large-scale capital injection plan to the market twice continuously. These stabilized the market fluctuations to some extent. Whether this earthquake would become a turning point of the high oil price and whether it would have big impact on yen exchange rate are two issues to be discussed in this paper. To analyze deeply the internal relations between changes in yen exchange rate caused by Japan's earthquake and price fluctuation of international crude oil, this research chooses middle rate of yen exchange rate during the 45 days around Japan's earthquake and price data of international crude oil to do an empirical study, uses VAR model and HP trend decomposition to estimate the mutual effect of yen exchange rate change and price fluctuation of international crude oil in this period, and predicts simply the trend of yen exchange rate and international crude oil price in the short or medium term.

\section{Literature Review}

Papers on the influence of natural disasters on economy are rare in the academia. This area grew up in fifties of the last century in the west, and at the beginning, the research only focused on the analysis of estimating the economic loss caused by natural disasters (Zhou, 2009). Brannen (1954) made groundbreaking contributions in this area by studying U.S. Texas catastrophe ( $\mathrm{Li}, 2011$ ). Since 1980, many economists began to put a high value on the medium and long term influence on economy. As an example, Bertrand (1993) proved that most countries' GDP increased by using data of natural disasters and economic growth of developing countries in 1960-1979, and reached an unexpected conclusion that disasters could accelerate economic growth (Benson, 1997). With regard to this conclusion, many economists with different opinions also explored this area and reached many useful conclusions. Benson (1997) ever conducted in-depth research on whether tornadoes and aridity affected Fiji economy by building an econometric regression model, and the result showed that natural disasters would have a long-term negative impact on a country's economy (Nagamatsu, 2002). In the same period, Japanese scholar Nagamatsu Shingo also did much empirical study, and his result was contrary to Benson (1997)'s hypothesis. He believes that the influence of natural disasters on economy should be divided into positive side and negative side. The positive side included recovery requirements, investment multiplier effect and accompanying technological innovation. The negative side referred to damage to capital stock and reduction of production rate, together with the attention paid to the developing stage of each country. The negative effect in developed countries lasted for a shorter time than that in developing countries while 
the positive effect in developing countries lasted for a longer time than that in developed countries (Yezer, 2000). Later academia did massive studies using data at different time from various countries. The official publishing of the monograph of Disaster Economics marked that this area had formally become one of economic research directions.

\section{Data Sources and Variables Setting}

This research will use the middle rate data of dollar: yen exchange rate and international crude oil price data in direct quotation. Middle rate data of dollar: yen exchange rate may come from statistical database of State Administration of Foreign Exchange, and the international crude oil price data comes from the weighted result of Brent crude oil price and NYBOT WTI light sweet crude oil price. There are no worldwide norms and standards for measuring international crude oil price in the studies on international crude oil price in the academia. World's major oil consumption and producing countries have a regional unified price of international crude oil considering their own national situation and the reference standards are not the same. Currently the main referential markets worldwide to measure international crude oil price are Brent crude oil market, Dubai crude oil market and New York crude oil market. Considering futures market scale and influence, Brent crude oil market and New York crude oil market would be ranked the first and the second, so this paper chooses international crude oil prices of these two big markets as main references. For convenience, this paper weights Brent crude oil price and New York crude oil futures (WTI) price of every trading day equally to get the final international crude oil price used in this paper. The data is trading data from February 14, 2011 to April 15, 2011 (festival and holiday rejected), which is just one month before and one month after the earthquake, so it's convenient to compare and study the data relationship before and after the earthquake. The trend of yen exchange rate and international crude oil price is as follows:

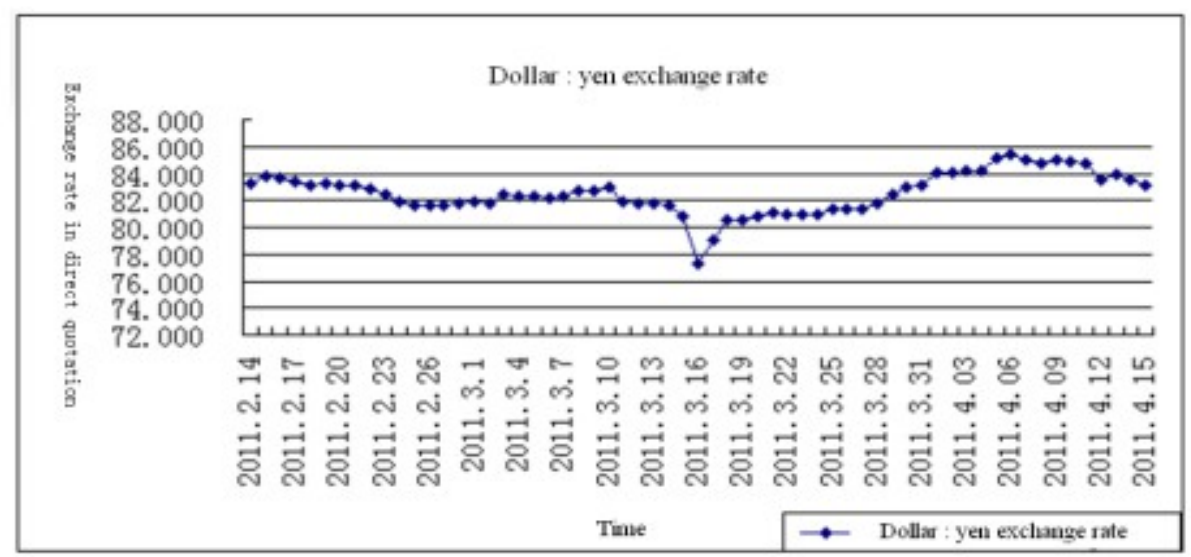

Figure 1. Chart of middle rate of dollar: yen exchange rate around Japan's earthquake (Data source:

State Administration of Foreign Exchange) 


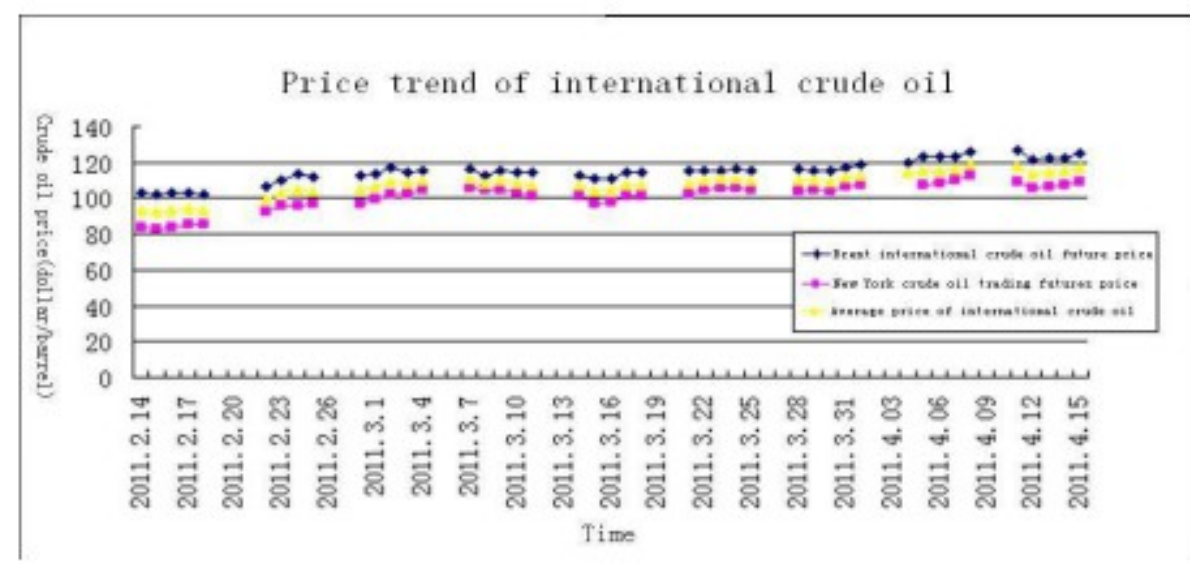

Figure 2. Chart of international crude oil price around Japan's earthquake (Data source: United States Department of Energy: http://tonto.eia.doe.gov)

The figure above shows: in a period of time before Japan's earthquake, the trend of yen exchange rate in direct quotation is relatively stable, and data is presented as a small shock. The whole trend is that yen rises slowly. From March 11 when the earthquake began, yen exchange rate shocked sharply suddenly and began to fall down, and reached a record low (1 dollar for 77.2 yen) on March 16. The quick and significant appreciation of yen directly intensified the chain reaction of global financial market. World stocks generally fell. Nikkei index saw the maximum drawdown of a single day by $10.55 \%$ on March 15 . So on March 18 , G7 announced to intervene yen jointly by injecting yen to global currency market, buying other currencies back, keeping the supply and demand of yen in balance in foreign exchange markets. Then the trend of yen exchange rate became stable slowly. On the other hand, international crude oil price showed a rising trend all the time. If the time around Japan's earthquake is divided into two stages, international crude oil price rose generally with large fluctuations before the earthquake, while in initial stage after the earthquake, the price fell down, and on March 17 the price rebounded sharply and then kept rising steadily. It could be visually found from the figures that: it seemed that Japan's earthquake had very limited impact on international crude oil price, with an unobvious extent. Only by calculating the change rate of international crude oil price can we found some obvious changes. So it requires further research on the relationship between them.

To study the relationship between yen exchange rate and international crude oil price further, sample variables should be set uniformly. Suppose yen exchange rate variable is $R E$, Brent crude oil future price variable is OPB, New York crude oil future price variable is OPW, and the international price variable is OP. The descriptive statistical results of each variable are as follows. 


\begin{tabular}{|c|r|r|r|r|r|}
\hline Variable & \multicolumn{1}{|c|}{ Maximum } & \multicolumn{1}{c|}{ Minimum } & \multicolumn{1}{c|}{ Average } & \multicolumn{1}{c|}{ Median } & \multicolumn{1}{c|}{$\begin{array}{c}\text { Standard } \\
\text { Deviation }\end{array}$} \\
\hline RE & 85.41 & 77.23 & 82.54 & 82.68 & 1.56 \\
\hline OPB & 126.46 & 102.20 & 114.70 & 115.19 & 6.33 \\
\hline OPW & 112.27 & 83.13 & 101.07 & 103.54 & 7.63 \\
\hline OP & 119.28 & 92.80 & 107.88 & 109.57 & 6.87 \\
\hline
\end{tabular}

Table 1. Descriptive statistical table of data variables (Data source: Organized and calculated according to statistical software reviews 6.0)

Following hypotheses are proposed on this basis.

- Hypothesis 1: Change of yen exchange rate in direct quotation and change of international crude oil have a positive correlation- that is when yen appreciates, international crude oil price increases; when yen devaluates, international crude oil price falls.

- Hypothesis 2: The trend of yen exchange rate has influence on the change of international crude oil price, but not the most important factor.

- Hypothesis 3: For the oil resources' strategic position and scarcity, Japan's earthquake won't make the international crude oil price fall continuously and the high oil price will go on.

\section{Empirical Model and Test}

If the hypothesis above is right, then such conclusion can be drawn: weak dollar compels international investors to choose safe-haven currency again. Yen has become a sovereign currency that performs the functions of world currency and international settlement to replace dollar, to some extent. And as economic globalization goes deeper, the economic stability of each nation-state will impact directly on international financial market stability. Information transfer wouldn't be distorted and expectation factors will play leading roles. To verify whether the above-mentioned hypothesizes are correct, we built vector autoregression model (VAR) between yen exchange rate as well as international crude oil price and HP filter decomposition model between them. EVIEWS6.0 is used to build the model and do relative tests.

\subsection{Unit Root Test}

For time series data, data stationarity is very important in later model building. Non-stationary series may cause spurious regression in least square parameter estimate, so the impact of 
change of time on variable should be eliminated. Unit root test can solve this problem by difference sequences. Common unit root tests mainly include ADF test and PP test. Here we choose ADF unit root to do stationary test on yen exchange rate RE and international crude oil price sequence OP.

\begin{tabular}{|c|c|r|r|l|}
\hline $\begin{array}{c}\text { Variable } \\
\text { Sequence }\end{array}$ & Method (C, T, K) & ADF Test Value & $\begin{array}{c}\mathbf{5 \%} \text { Critical } \\
\text { Value }\end{array}$ & \multicolumn{1}{|c|}{ Result } \\
\hline RE & (c, 0,0$)$ & -1.72 & -2.92 & not stationary \\
\hline Ln RE & (c, 0,0$)$ & -1.72 & -2.92 & not stationary \\
\hline Ln RE & (c, 0,1$)$ & -5.98 & -2.93 & stationary \\
\hline OP & (c, 0,0$)$ & -1.68 & -2.92 & not stationary \\
\hline Ln OP & (c, 0,0$)$ & -1.87 & -2.92 & not stationary \\
\hline$\Delta$ Ln OP & (c, 0,1$)$ & -5.66 & -2.93 & stationary \\
\hline
\end{tabular}

Note: $(C, T, K)$ in unit root test present intercept term, trend term and lag intervals for endogenous. Lag intervals for endogenous are determined according to AIC and SC minimum criterion.

Table 2. ADF unit root test chart

From the unit root test we can know that original yen exchange rate sequence and original international crude oil price sequence are both non-stationary sequences, so smooth adjustment should be made. To avoid influence of multicollinearity, this research chooses logarithm sequence of yen exchange rate and international crude oil price for the test. These sequences become stationary after first-order difference, which means there is integrated of order 1 relationship between them.

\subsection{Determination of VAR Lag Model Order $P$}

A condition for building VAR model is to know lag structure among each variable. Lag structure of VAR (P) can be determined by minimum criterion of Akaike information criterion (AIC) and Schwarz criterion (SC). 6 order lag is chosen for the test so as not to lose many degrees of freedom of the samples. Test results are as follows:

\begin{tabular}{|c|c|c|c|c|c|c|}
\hline Lag order & LogL & LR & FPE & AIC & SC & HQ \\
\hline $\mathbf{0}$ & 178.59 & NA & $4.00 \mathrm{e}-07$ & -9.06 & -8.97 & -9.02 \\
\hline $\mathbf{1}$ & 239.84 & $113.08^{* *}$ & $2.12 \mathrm{e}-08$ & -11.99 & $-11.74^{* *}$ & $-11.90^{* *}$ \\
\hline $\mathbf{2}$ & 244.50 & 8.131 & $2.06 \mathrm{e}-08^{* *}$ & $-12.03 * *$ & -11.60 & -11.87 \\
\hline $\mathbf{3}$ & 246.31 & 2.97 & $2.31 \mathrm{e}-08$ & -11.91 & -11.31 & -11.70 \\
\hline $\mathbf{4}$ & 247.53 & 1.88 & $2.69 \mathrm{e}-08$ & -11.77 & -11.00 & -11.49 \\
\hline $\mathbf{5}$ & 248.22 & 0.98 & $3.24 \mathrm{e}-08$ & -11.60 & -10.66 & -11.26 \\
\hline $\mathbf{6}$ & 250.01 & 2.38 & $3.71 \mathrm{e}-08$ & -11.49 & -10.38 & -11.09 \\
\hline
\end{tabular}

Note: $* *$ means the lag order determined by minimum criterion

Table 3. Test table of VAR lag model order $\mathrm{P}$ 
The above table shows that the lag order determined by minimum criterion of likelihood ratio test (LR), final prediction error (FPE), Akaike information criterion (AIC), Schwarz criterion (SC) is 2. So we can build VAR (2) model between yen exchange rate (LnRE) and international crude oil price (LnOP). The model is as follows:

$$
\begin{aligned}
& L n R E_{t}=0.912 L n R E_{t-1}-0.077 L N E_{t-2}+0.213 * L n O P_{t-1}-0.184 L n O P_{t-2}+0.59 \\
& \text { sign: (positive) (negative) (positive) (negative) } \\
& L n O P_{t}=-0.225 L n R E_{t-1}+0.248 L n R E_{t-2}+1.06 \operatorname{LnOP}_{t-1}-0.134 L n O P_{t-2}+0.271 \\
& \text { sign: (negative) (positive) (positive) (negative) }
\end{aligned}
$$

From VAR (2) model we can judge preliminarily: the fluctuation of yen exchange rate seems to be caused by changes in itself. The consistency between fluctuation sign of yen exchange rate and fluctuation sign of international crude oil price is not obvious, so the truth of the abovementioned hypotheses cannot be judged only by the model result. Further research is needed

\subsection{Impulse Response Function}

From the impulse response result, fluctuations of yen exchange rate are mainly determined by early trend of yen exchange rate, which shows that yen exchange rate is sticky price and exists for a long time. Fluctuations of international crude oil price have little effect on the trend of yen exchange rate and the exchange rate maintains stable basically. As for international crude oil price, early trend of crude oil price and fluctuations of yen exchange rate both have big impacts on current international crude oil price. The impact of yen exchange rate on international crude oil price continues for a long time. Early price of international crude oil price has big impact on the current one. But considering the absolute amplitude, the impact of yen exchange rate fluctuations on the international crude oil price is much bigger than that of early crude oil price on current price. At the same time the results find that both impact mainly by fluctuations of yen exchange rate and the impact mainly by fluctuations of international crude oil price have consistent positive effect. This result preliminarily verifies the reasonability of hypothesis 1 aforementioned. 
Response to Cholesky One S.D. Innovations \pm 2 S.E.
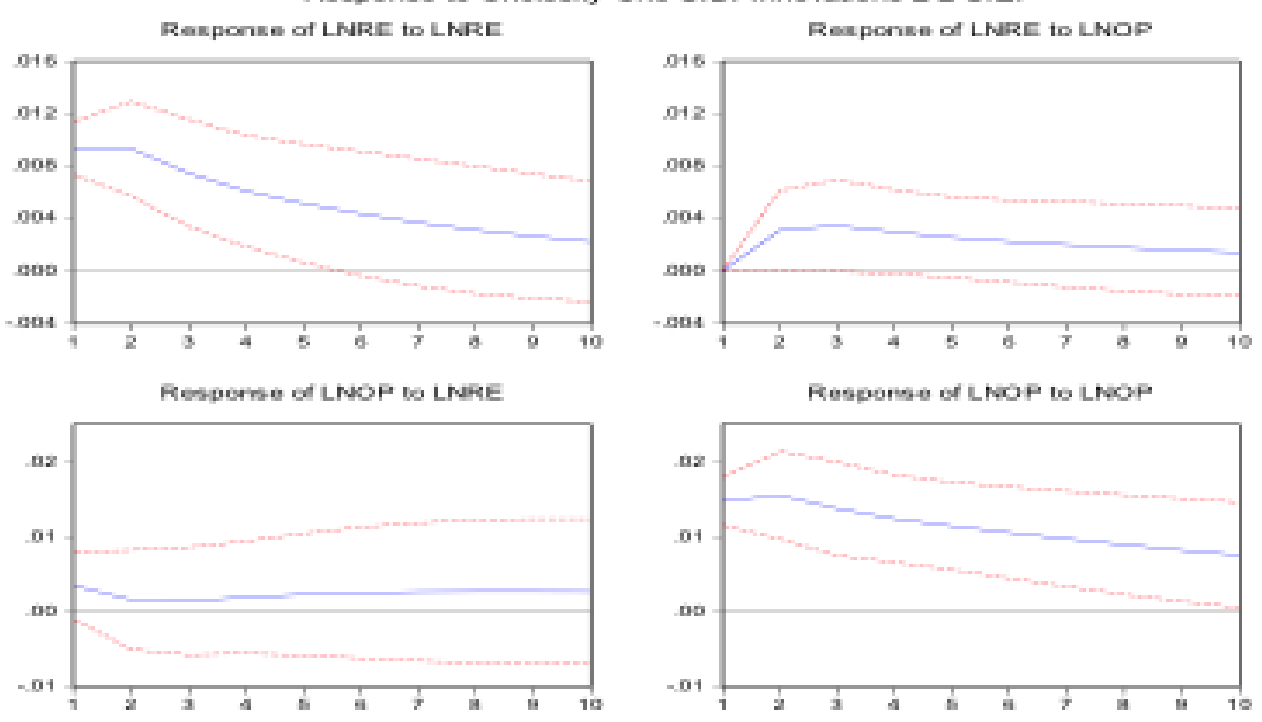

Figure 3. Impulse response diagram of yen exchange rate and international crude oil price fluctuations

\subsection{Variance Decomposition}

The above-mentioned impulse response function can only show simply impact of fluctuation of yen exchange rate and international crude oil price on themselves or the other, but cannot give a quantitative amplitude index of the impact. So we can analysis the contribution degree of the mutual influence of yen exchange rate changes and international crude oil price fluctuations through variance decomposition, and give an indicator of the impact importance measured by deviation. [3] Results of Variance decomposition on VAR (2) model are as follows:

Variance Decomposition
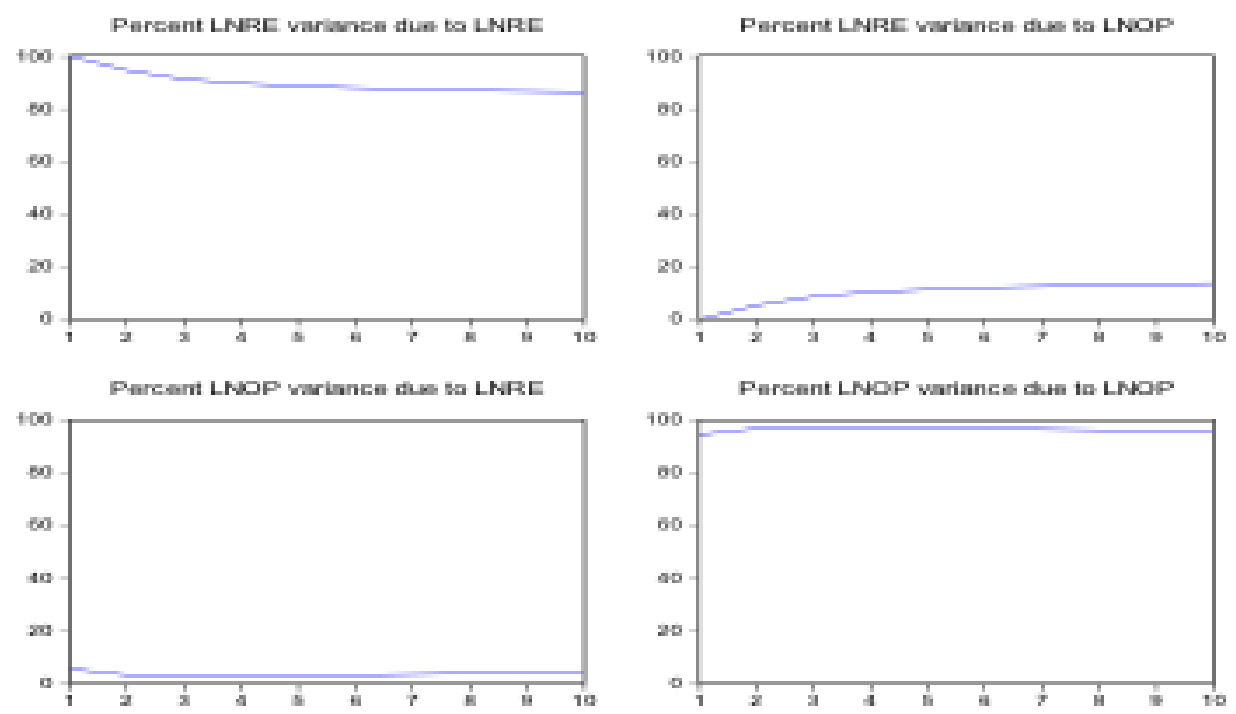

Figure 4. Schematic diagram of variance decomposition of yen exchange rate changes and international crude oil price fluctuations 
Results of variance decomposition show that: in the influencing factors of international crude oil price fluctuation, the factor of yen exchange rate is $13.54 \%$ of all influencing factors at the maximum, which shows that the trend of yen exchange rate around Japan's earthquake really has great influence on fluctuations of international crude oil price. But the author thinks, the fact that deviation percent is only $13.54 \%$ means there are more factors influencing international crude oil price, yen exchange rate is only one of the major factors. This result verifies that the hypothesis 2 is true. And the result also finds that the fluctuation of yen exchange rate caused by fluctuations of international crude oil price is only $4.5 \%$ of the whole fluctuation deviation in that period. Changes of international crude oil price have little influence on the trend of yen exchange rate.

\subsection{HP Filter Trend Analysis}

The above-mentioned 2 hypotheses are verified. But this research pays more attention to the short and medium term trend of yen exchange rate and international crude oil price after Japan's earthquake. This problem cannot be solved perfectly by VAR (2) model. So we make simple prediction on the trend yen exchange rate and international crude oil price in this period and afterwards by using HP filter trend decomposition model. HP (Hodrick-Prescott) filter method was first proposed by Hodrick and Prescott (1980) to distinguish the trend component and volatility component in economic time series variable, and to study and judge the short and medium term trend of the sequence. Suppose yen exchange rate $R E_{t}$ in this research, the economic time series is to be studied, then we get the following result from HP filter

$$
R E_{t}=R E_{t}^{T}+R E_{t}^{C}
$$

Among them: $R E_{t}{ }^{T}$ is the trend component of yen exchange rate; $R e_{t}{ }^{c}$ is volatility component (error component) of yen exchange rate.

Using this theorem we carry out HP filter decomposition on yen exchange rate series and international crude oil price series around Japan's earthquake. Results are as follows: 
Hodrick-Prescott FHer (lambda=6812100)

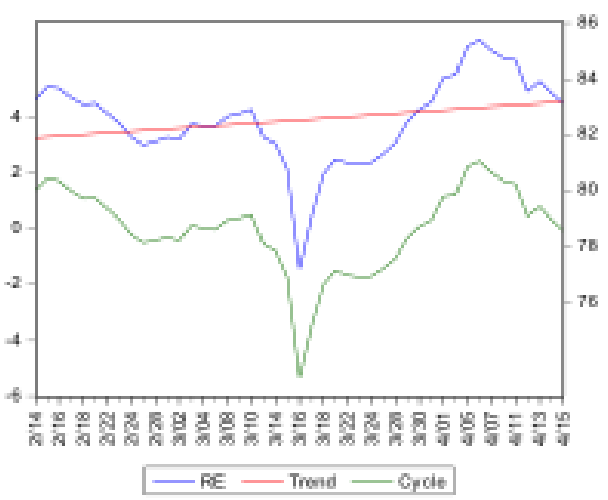

Hodrick-Prescott Fither (tumbods=6si2100)

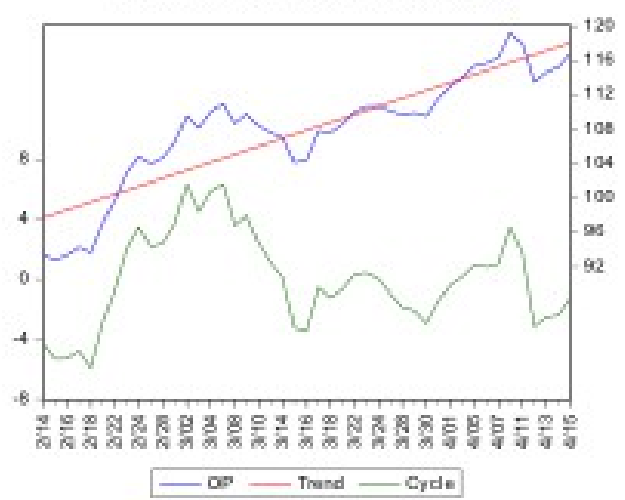

Figure 5. HP filter trend decomposition results of the trends of yen exchange rate and international crude oil price

The decomposition results show: in short and medium term, yen exchange rate will keep stable and appreciate slowly, but there is target zone for the exchange rate fluctuation. The trend component of yen exchange rate fluctuation basically stays around 1 dollar to 83 yen, and won't fluctuate sharply in the medium term. The real exchange rate fluctuations of yen are caused mainly by the volatility component and it is basically consistent with real fluctuating amplitude of yen market. There is a close relation of linkage of the two. As for the international crude oil price, its real price fluctuation is caused jointly by trend component and volatility component. If the influence of volatility component is ignored, the international crude oil price still has a big appreciation space in the short and medium term. There is upward pressure for international crude oil price and exceeding 120 dollar/barrel is the short term trend. The volatility component firstly synchronizes with the real crude oil price and then deviates from it. Regarding the consistency, the two have the trends in the same direction, but there is a gradually expanding gap between the volatility component and the real market price. The expanding gap means the relationship between the real price of international crude oil and volatility component slowly weakens, while the trend component contribute more obviously to the whole price trend. From the view of time-point, the volatility component of yen exchange rate fluctuations reacts quickly and obviously to the earthquake, and makes the yen exchange rate decrease sharply, while international crude oil price reacts slowly relatively, and its volatility component has little influence on the real price of international crude oil, so this result proves hypothesis 3 perfectly. 


\section{Conclusions}

This paper studies the influence of yen appreciation on international crude oil price changes around Japan's earthquake by empirical analysis of international crude oil price fluctuations and yen exchange rate changes. The results of empirical study find that: in the period around Japan's earthquake, yen exchange rate changes have a powerful positive impact on the fluctuations of international crude oil price. $13.54 \%$ of the international crude oil price fluctuations are directly caused by yen exchange rate fluctuations. There is upward pressure for international crude oil price in the short and medium term. The impact of international crude oil price fluctuations on yen exchange rate fluctuations is a long-term, stable and positive one, but its percent in the whole deviation of yen exchange rate fluctuations is negligible. There is a relatively stable target zone for yen exchange rate in the medium and long term and the rate won't fluctuate sharply. Generally Japan's earthquake didn't produce serious impacts on international crude oil price, while had great short-term impact on yen exchange rate, which was reflected in the change of volatility component of HP trend decomposition results. As economic globalization goes deeper, the influence of natural disasters on international financial market and world economy will become more and more obvious. It has a great revelatory meaning to studying further each kind of natural disaster's impacts on international financial market and world economics.

\section{Acknowledgments}

The writing of this paper has been supported by the major special projects of the Ministry of Education "Industrial safety engineering research" (item number: 239010522) and the special projects of the Ministry of Education "Research of Chinese credit rating system" (item number: 239005522).

\section{References}

Albala, B. (1993). Political Economy of Large Natural Disasters: with Special Reference to Developing Countries. Oxford; UK: Clarendon Press.

Benson, C. (1997). The Economic Impact of Natural Disasters in Fiji. Working Paper 97, Overseas Development Institute, 1997.

Brannen, T.R. (1954). Economics aspects of the Waco, Texas Disater of May 11, 1953. Research Report of Department of Sociology, University of Texas, 1954(2), 1-40. 
Li, H. (2011). Empirical Research on Relationship between Natural Disasters and Economic Growth - Based on Analysis of Panel Data of 14 Countries in 1970 to 2008. Prices Monthly, $1,48-49$.

Nagamatsu, S. (2002). Ways of Financial Support for the Reconstruction and Beforehand Prevention of Natural Disasters in Developing Countries. Commissioned research report.

Yezer, A.M. (2000). The Economics of Natural Hazards. Center for Economic Research Discussion Paper NO.98-11, 2000, 1-30.

Zhou, X. (2009). An Overview on Influence of Natural Disaster on Economic Growth. Journal of Catastrophology, 3, 113-114.

Journal of Industrial Engineering and Management, 2014 (www.jiem.org)

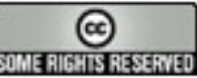

Article's contents are provided on a Attribution-Non Commercial 3.0 Creative commons license. Readers are allowed to copy, distribute and communicate article's contents, provided the author's and Journal of Industrial Engineering and Management's names are included. It must not be used for commercial purposes. To see the complete license contents, please visit http://creativecommons.org/licenses/by-nc/3.0/. 